
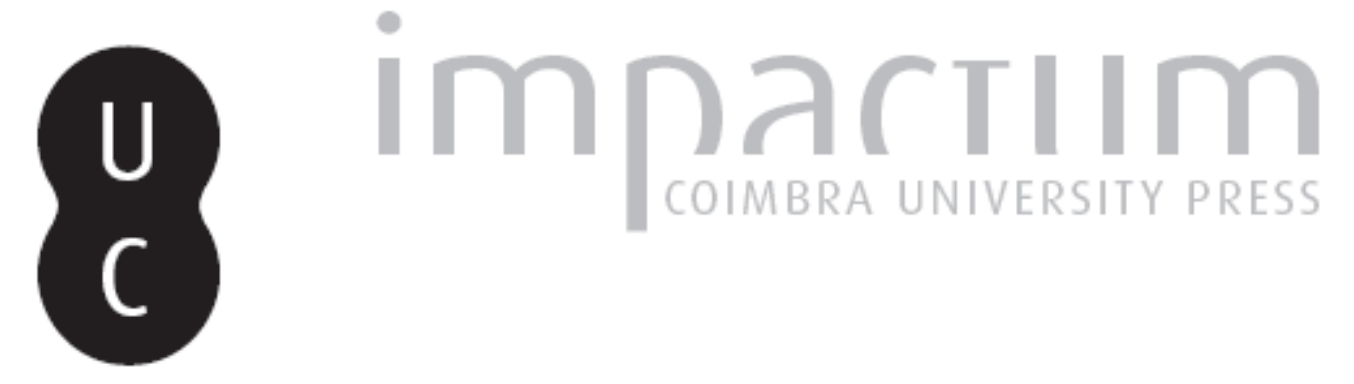

\title{
Vaidades nos conventos femininos ou das dificuldades em deixar a vida mundana (séculos XVII-XVIII)
}

\author{
Autor(es): $\quad$ Braga, Isabel M. R. Mendes Drumond \\ Publicado por: Centro de História da Sociedade e da Cultura \\ URL \\ persistente: \\ URI:http://hdl.handle.net/10316.2/39523 \\ DOI: \\ DOI:http://dx.doi.org/10.14195/1645-2259_10-1_13
}

Accessed : $\quad$ 26-Apr-2023 01:30:19

A navegação consulta e descarregamento dos títulos inseridos nas Bibliotecas Digitais UC Digitalis, UC Pombalina e UC Impactum, pressupõem a aceitação plena e sem reservas dos Termos e Condições de Uso destas Bibliotecas Digitais, disponíveis em https://digitalis.uc.pt/pt-pt/termos.

Conforme exposto nos referidos Termos e Condições de Uso, o descarregamento de títulos de acesso restrito requer uma licença válida de autorização devendo o utilizador aceder ao(s) documento(s) a partir de um endereço de IP da instituição detentora da supramencionada licença.

Ao utilizador é apenas permitido o descarregamento para uso pessoal, pelo que o emprego do(s) título(s) descarregado(s) para outro fim, designadamente comercial, carece de autorização do respetivo autor ou editor da obra.

Na medida em que todas as obras da UC Digitalis se encontram protegidas pelo Código do Direito de Autor e Direitos Conexos e demais legislação aplicável, toda a cópia, parcial ou total, deste documento, nos casos em que é legalmente admitida, deverá conter ou fazer-se acompanhar por este aviso.

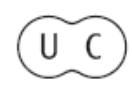




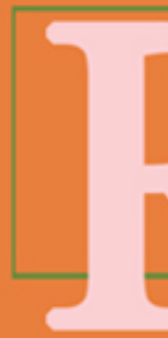

\section{evista de História}

da Sociedade e da

Cultura

\section{Tomo I}

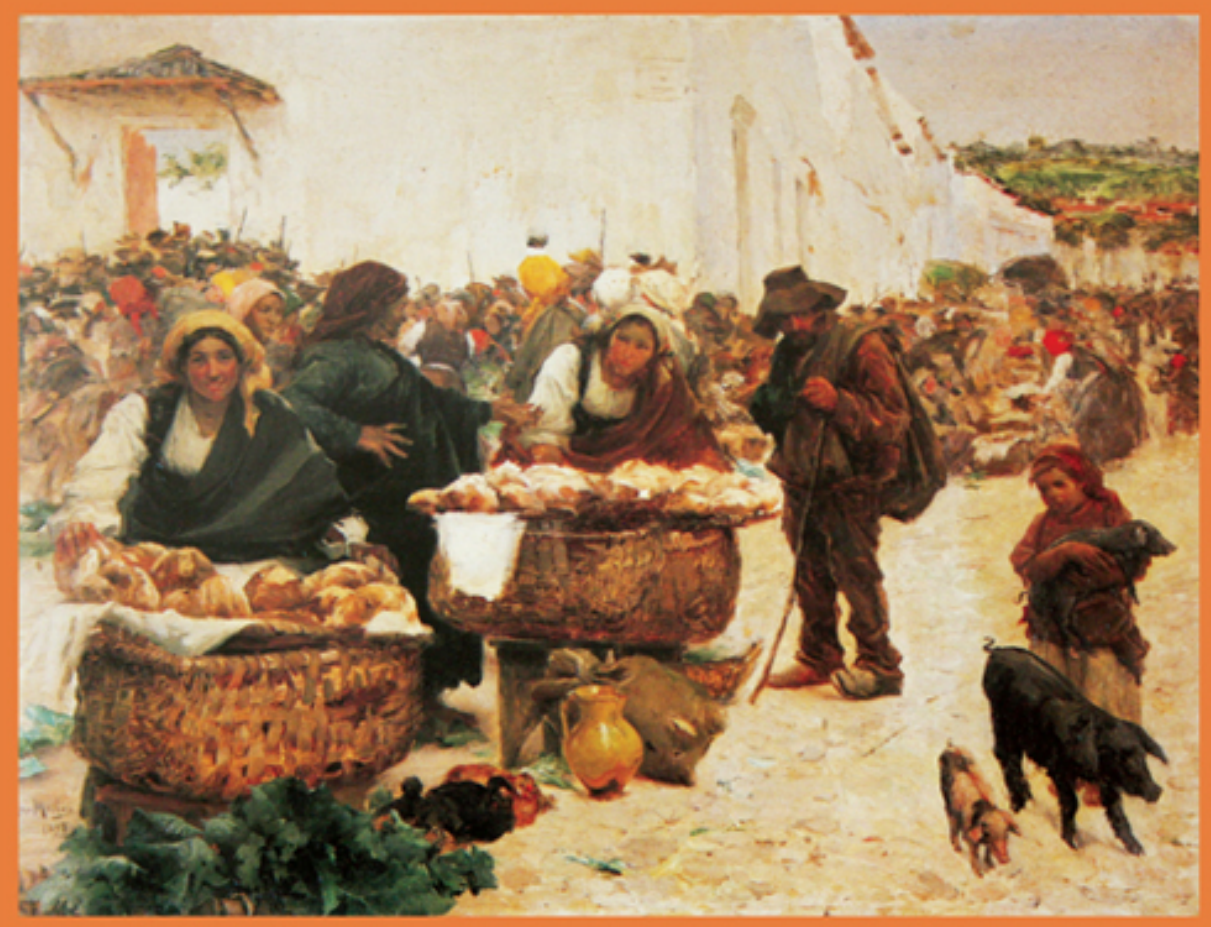

Centro de História da Sociedade e da Cultura Universidade de Coimbra

Coimbra 


\title{
Vaidades nos Conventos Femininos ou das Dificuldades em deixar a Vida Mundana (séculos XVII-XVIII)*
}

\author{
Isabel M. R. Mendes Drumond Braga \\ Professora Auxiliar com agregação da Faculdade de Letras da Universidade de Lisboa \\ isabeldrumondbraga@hotmail.com \\ Texto recebido em/ Text submitted on: 14/01/2010 \\ Texto aprovado em/ Text approved on: 18/02/2010
}

\section{Resumo/Abstract:}

Através deste artigo, propomo-nos estudar os comportamentos proibidos mas frequentes nas casas religiosas femininas da Época Moderna. Efectivamente, nem sempre se respeitavam as regras, de tal modo que visitas e devassas tornam visíveis comportamentos desviantes em especial no que se refere a aspectos como a introdução de alterações nos hábitos, o uso de peças de vestuário e de jóias afins aos das leigas, o recurso a cosméticos, a violação da clausura, a posse de animais de estimação, a representação de comédias e até o comércio de doces. Ano após ano, os visitadores criticavam tais comportamentos, exortavam as religiosas a seguirem as regras e até as ameaçavam de penas diversas. Porém, na maior parte dos casos, a resistência era a resposta.

From an historical approach, we propose to study forbidden actions of nuns in Portuguese convents in the Modern Era. The lives of these women were governed by rules, which they did not always respect. Such violations often resulted in deviating behaviors, involving religious habits, lay clothes and jewelry, cosmetics, pet dogs and cats, violation of cloister, acting in comedy plays or even selling sweets. Year after year, the visitors criticized such behavior, extorting the nuns to respect the rule, and even threatened them with punishment, but most of them resisted.

Palavras chave/Keywords:

Braga; Clausura; Conventos femininos; Vaidades.

Braga; Enclosure; Nunneries; Vanities.

* Versão desenvolvida do texto inédito "Des Vanités dans les Couvents Féminins ou des Difficultés de quitter la Vie Mondaine (XVII ${ }^{\mathrm{e}}$ - XVIII ${ }^{\mathrm{e}}$ siècles)" apresentado ao Colloque Interdits et Genre. Constructions, Représentations et Pratiques du Féminin et du Masculin, realizado em Tours em Maio de 2009. 
1. Nem sempre a população religiosa que integrava conventos e mosteiros tinha vocação para se dedicar a uma vida abnegada, de oração e retiro do mundo. Efectivamente, ingressar numa casa religiosa podia ser o resultado de pressões familiares e de estratégias patrimoniais, de tal modo que conventos e mosteiros, além de constituírem oportunidades para filhas segundas da nobreza, a quem não fora possível casar, e de integrarem mulheres de outros grupos sociais de acordo com as exigências de cada estabelecimento, eram, para certas mulheres de então, locais de educação na juventude, espaços de retiro espiritual durante o casamento e refúgio temporário ou definitivo na viuvez ${ }^{1}$. Porém, os problemas mais significativos dentro dos espaços conventuais eram ocasionados pelas freiras e não pelas mulheres que ali ficavam apenas temporariamente.

Quer os superiores das Ordens quer os bispos procuravam visitar as instituições, prática a que foi prestada mais atenção após o Concílio de Trento. Em algumas casas o que viam era alarmante: disputas nas eleições para abadessa, lutas pelas celas das religiosas que faleciam, cobrança de propinas às noviças quando professavam, violação da clausura, brigas provocadas por ciúmes, insultos e até agressões físicas, posse de animais dentro do convento, realização de comédias e autos em ocasiões festivas, descuidos com os hábitos, uso de cosméticos e até práticas homossexuais, eram bastante mais comuns do que poderíamos pensar. Advertências, censuras e excomunhões, ou seja, mecanismos de coerção, nem sempre eram eficazes, tanto mais que a manutenção dos comportamentos desviantes era uma realidade, bem patente nas visitas e devassas levadas a efeito ao longo da Época Moderna.

Se a prática de visitar as casas religiosas foi anterior ao Concílio de Trento $^{2}$, durante o mesmo insistiu-se nas exigências que deveriam ser tidas

1 BEAUVALET-BOUTOUYRIE, Scarlet - Etre Veuve sous l'Ancien Régime. Paris: Belin, 2001, p. 283; EVANGELISTI, Silvia - Nuns. A History of Convent Live 1450-1700. Oxford: Oxford University Press, 2007, p. 25.

2 Cf. MEA, Elvira Cunha de Azevedo - A Igreja em Reforma. In DIAS, João José Alves (ed.) - Portugal do Renascimento à Crise Dinástica (= SERRÃO, Joel, MARQUES, A. H. de Oliveira (ed.), Nova História de Portugal, V). Lisboa: Presença, 1998, p. 413-446. $\mathrm{Na}$ concretização das determinações conciliares, além do cardeal infante, que era igualmente arcebispo de Évora, destacou-se também D. frei Bartolomeu dos Mártires enquanto arcebispo de Braga. Cf. sobre o primeiro, SILVA, Amélia Maria Polónia da - O Cardeal Infante 
em conta no momento de admitir as candidatas a freiras, desde a formação intelectual e doutrinária, o dote, a vocação, passando pela reflexão acerca do acto de professar. Por outro lado, ao relembrar aos bispos e superiores das Ordens a necessidade de visitar as casas e ao tornar essa prática rotineira tentou disciplinar-se o comportamento da população religiosa. Efectivamente, após Trento ${ }^{3}$, o clero desempenhou uma acção mais actuante e efectiva no que se refere ao controlo do comportamento dos fiéis, assunto naturalmente ligado ao discurso de natureza política ${ }^{4}$. Neste sentido, as propostas historiográficas dos últimos anos têm tido em linha de conta os diferentes tipos de controlo moral e social e os seus diferentes agentes, bem como as áreas de cooperação e conflito verificadas entre os vários intervenientes no processo de disciplinamento social ${ }^{5}$.

D. Henrique, Arcebispo de Évora. Um Prelado no Limiar da Viragem Tridentina. Porto: Provas de Aptidão Pedagógica e Capacidade Científica, 1989; Idem - Recepção do Concílio de Trento em Portugal: as Normas Enviadas pelo Cardeal D. Henrique aos Bispos do Reino, em 1553. Revista da Faculdade de Letras. História, 2. ' série, 7 (1990), p. $133-$ -143; BRAGA, Isabel M. R. Mendes Drumond - A Visita da Inquisição a Braga, Viana do Castelo e Vila do Conde em 1565. Revista de la Inquisición. 3 (1994), p. 29-67. Sobre o segundo, cf. CASTRO, José de - Venerável Bartolomeu dos Mártires (Arcebispo e Senhor de Braga). Porto: Oficina Gráfica da Casa Nun'Alvares, 1946; ROLO, Raul de Almeida O Bispo e a sua Missão Pastoral. Segundo D. frei Bartolomeu dos Mártires. Porto: Edição do Movimento Bartolomeano, 1964; Frei Bartolomeu dos Mártires (1514-1590). Catálogo Biblio-Iconográfico. Lisboa: Biblioteca Nacional, 1991; CASTRO, Aníbal Pinto de - Fra Bartolomeo dei Martiri, un Vescovo Tridentino per la Modernità. D. Frei Bartolomeu dos Mártires, um Bispo Tridentino para a Modernidade. Roma, Coimbra: [s.n.], 1999.

3 Em Portugal os decretos tridentinos foram adoptados como lei durante a regência do cardeal infante D. Henrique na menoridade de D. Sebastião, reforçando a influência do direito canónico na legislação portuguesa não obstante a oposição de alguns sectores, incluindo de algumas facções do clero. A bula de Pio V, de 26 de Janeiro de 1564, na qual confirmou o concílio, foi solenemente lida e publicada na sé de Lisboa pelo próprio cardeal. Da iniciativa do regente foi igualmente a publicação dos decretos em latim e em português, ambas as edições de 1564 .

4 CARDIM, Pedro - Politics and Power Relations in Portugal (Sixteenth-Eighteenth Centuries). Parliaments. Estates and Representations. 13, n. ${ }^{\circ} 2$ (1993), p. 95-108.

5 Efectivamente, se a origem destes conceitos é alemã e se, inicialmente, foram utilizados na história política, depressa o âmbito foi alargado à história religiosa, tanto mais que as relações entre o político e o religioso foram marcantes ao longo de toda a Época Moderna, pois os fenómenos religiosos só podem ser compreendidos de forma relacional. Cf. SHULZE, Winfried - Il Concetto di 'Disciplinamento Sociale nella prima Età Moderna' in Gerhard Oestreich. Annali dell'Istituto Storico Ítalo-Germanico in Trento. 18 (1992), p. 371-411; REINHARD, Wolfgang - Disciplinamento Sociale, Confessionalizzazione, Modernizzazione. Un Discurso Storiografico. In PRODI, Paolo e PENUTI, Carla (ed.) - Disciplina dell'Anima, 
Conduzir as condutas, quer de leigos quer de eclesiásticos, foi uma tarefa que implicou esforços conjuntos da Coroa e da Igreja, os quais passaram pela utilização de formas e instrumentos de difusão do discurso religioso, umas de carácter repressor, tais como visitas pastorais e inquisitoriais e censura de livros e outras de carácter pedagógico e persuasivo, tais como missões do interior, pregações, ensino da doutrina e confissões, sem esquecer a divulgação de livros de devoção, catecismos, hagiografias, imagens e até peças de teatro com fins evangelizadores ${ }^{6}$. O objecto do nosso estudo centra-se nas resistências ao disciplinamento no universo conventual feminino a partir de sondagens levadas a efeito na arquidiocese de Braga, de meados do século XVII a meados da centúria seguinte, comparando com alguns resultados já obtidos para outros pontos do país.

2. Independentemente das regras de cada ordem religiosa, publicaram-se obras com intuitos específicos de disciplinar o comportamento das freiras e de moldar a espiritualidade de todos os que viviam ou não em espaços conventuais ${ }^{7}$. Não obstante, os desvios às normas e os desrespeitos das regras eram uma constante atestada pela repetição das recomendações e das proibições, indícios claros da persistência das infracções. Independentemente da regra seguida, havia constantes, tais como, e de entre outras, a obrigatoriedade de clausura e de castidade, a obrigação de usar hábitos de acordo com o prescrito, de manter contactos cordiais com as restantes freiras e de ocupar honestamente os tempos livres. Porém, o disciplinamento das comunidades era difícil e as resistências faziam sentir-se com muita veemência.

Se ingressar numa casa religiosa feminina implicava, naturalmente, o abandono do mundo, violar a clausura - que significava, sobretudo, a eliminação de algumas oportunidades de comportamentos escandalosos - era uma tentação que teria que ser banida tal como a presença de pessoas estranhas

disciplina del Corpo e Disciplina della Società tra Medioevo ad Età Moderna. Bolonha: Società Editrice il Mulino, 1994, p. 101-123; SCILLING, Heinz - Chiese Confessionali e Discilinamento Sociale. Un Bilancio Provvisorio della Ricerca Storica. In PRODI, Paolo e PENUTI, Carla (ed.) - Disciplina dell'Anima, disciplina del Corpo..., p.125-160.

6 Uma síntese desta realidade em Portugal, pode ser vista na obra de PALOMO, Federico - A Contra-Reforma em Portugal 1540-1700. Lisboa: Horizonte, 2005.

7 Cf. CARVALHO, José Adriano de (ed.) - Bibliografia Cronológica da Literatura de Espiritualidade em Portugal: 1500-1700. Porto: Instituto de Cultura Portuguesa, 1988. 
aos conventos, vivendo entre as freiras. Neste último caso, estipulavam-se condições, nomeadamente em relação ao sexo e à idade bem como ao tempo de permanência. Mas, nem sempre as determinações eram cumpridas e não raro a mundanização foi objecto de comentários, inclusivamente por parte de estrangeiros ${ }^{8}$. Por exemplo, através da visita de D. Sebastião de Matos de Noronha ao Convento de Nossa Senhora dos Remédios, de Braga, em 1637, fica a saber-se que algumas freiras gritavam nos capítulos e tentavam contactar com o exterior ${ }^{9}$, enquanto em 1724, D. Rodrigo de Moura Teles notava, escandalizado, que as religiosas de Santa Clara, de Guimarães, em conjunto com as criadas "[a]tirão com pinhoens e confeitos do coro para a gente que esta na igreja acção tão escandaloza e alheya ao estado religiozo e da caza de Deos que lhe não dariamos credito se o não vissemos tão justificado" 10 .

Outra preocupação, por vezes ligada à quebra da clausura, referia-se à castidade. Se a principal preocupação era no sentido de evitar contactos com o sexo masculino, mesmo entre mulheres a questão nem sempre era totalmente pacífica. Não terá sido por acaso que Rouillé, embaixador de França em Portugal, afirmou ser frequente o amor entre religiosas que se tratavam por manas ${ }^{11}$ e que frei Lucas de Santa Catarina tenha referido o mesmo assunto embora com uma linguagem mais violenta ${ }^{12}$. Por outro lado, algumas visitas e devassas referiram ciúmes e insinuaram mesmo práticas homossexuais e suas consequências no âmbito da vida conventual. Por exemplo, na de 1672, levada a efeito por D. Veríssimo de Lencastre,

8 Vejam-se as críticas de Joaquin Le Grand, secretário do embaixador de França em Portugal, expressas no final do século XVII, em relação às freiras de Odivelas. Cf. BRAGA, Isabel M. R. Mendes Drumond - Impressões de Portugal nas Correspondências de Le Grand e de Rouillé (1694-1700). Arquivos do Centro Cultural Português. 32 (1993), p. 586. Sobre a clausura entre as mulheres leigas, cf. LOPES, Maria Antónia - Mulheres, Espaço e Sociabilidade. A Transformação dos Papéis Femininos em Portugal à luz das Fontes Literárias (segunda metade do século XVIII). Lisboa: Livros Horizonte, 1989, p. 46-65. Para outros espaços, nomeadamente Veneza, cf. LAVEN, Mary-Monache. Vivere in Convento nell'Età della Controriforma, tradução de Federico Barbierato. Bolonha: Il Mulino, 2004.

9 Braga, Arquivo Distrital de Braga (ADB), Visitas e Devassas, liv. 19, fol. 20.

${ }^{10}$ Braga, ADB, Visitas e Devassas, liv. 68, fol. 73.

${ }^{11}$ BRAGA, Isabel M. R. Mendes Drumond - Impressões de Portugal nas Correspondências..., p. 586.

${ }^{12}$ RODRIGUES, Graça Almeida - Literatura e Sociedade na Obra de Frei Lucas de Santa Catarina (1692-1740). Lisboa: Imprensa Nacional Casa da Moeda, 1983, p. 199. 
arcebispo de Braga, ao convento de Santa Clara, de Guimarães, pode lerse que o visitador proibiu que duas ou mais religiosas partilhassem cama, salvo sendo irmãs, mais ordenando que houvesse uma cela para cada freira e, enquanto tal não se pudesse verificar, não se aceitassem mais freiras ${ }^{13}$. Anos mais tarde, em 1743, numa outra visita à mesma casa, desta feita por D. Eugénio Botto da Silva, coadjutor do arcebispado, algumas freiras testemunharam que certas religiosas "sam com outras com particullar amizade [...] e tratão com outras relligiozas e tomão satisfação não so de pallavra mas as vezes também de mãos arranhando-se o que sabe pello ver e estranhar muito porque não havia no seu tempo estas amizades"14. E o problema manteve-se pois, em 1759, na devassa levada a cabo pelo Doutor Domingos Martins da Cruz Marques, desembargador e juiz dos casamentos, apurou-se, por exemplo, que "algumas rellegiozas costumão dormir duas em huma cella para o que alegão cauzas que não sabe se são verdadeiras porem sempre ha algum escandalo na facilidade com que se lhe da diligencia" ${ }^{15}$.

Independentemente de ciúmes, as freiras nem sempre se tratavam com a devida correcção. Os estatutos que tinham detido no mundo secular eram, não raras vezes, levados para o convento ${ }^{16}$. Assim, brigas e injúrias fizeram

${ }^{13}$ Braga, ADB, Visitas e Devassas, liv. 68, fol. 29. O mesmo arcebispo fez idêntica proibição em 1670, em relação ao convento de Nossa Senhora da Conceição de Braga. Cf. Braga, ADB, Visitas e Devassas, liv. 18, fol. 4. A mesma proibição fora feita antes, em 1643, por D. Sebastião de Matos de Noronha e, em 1705, por D. Rodrigo de Moura Teles, em relação ao convento de Nossa Senhora dos Remédios de Braga. Cf. Braga, ADB, Visitas e Devassas, liv. 19, fols 23 e 79, respectivamente.

${ }^{14}$ Braga, ADB, Visitas e Devassas, liv. 75, fol. não numerado.

${ }^{15}$ Braga, ADB, Visitas e Devassas, liv. 73, fol. não numerado. A questão da homossexualidade feminina colocava-se igualmente nos recolhimentos e, naturalmente, no século. Cf. BRAGA, Paulo Drumond - Dois casos de Homossexualidade Feminina no Portugal Quinhentista. Vértice, II série, 72 (1996), p. 87-90; Idem, Casas de Deus ou antros do Demónio? Homossexualidade feminina em mosteiros e conventos (séculos XVI-XVIII). In Turres Veteras X. História do Sagrado e do Profano. Torres Vedras: Câmara Municipal de Torres Vedras, [Lisboa]: Universidade de Lisboa, Faculdade de Letras, Instituto de Estudos Regionais e do Municipalismo Alexandre Herculano, Edições Colibri, 2008, p. 89-94; LOPES, Maria Antónia - Repressão de Comportamentos Femininos numa Comunidade de Mulheres - Uma Luta Perdida no Recolhimento da Misericórdia de Coimbra (1702-1743). Revista Portuguesa de História, 37 (2005), p. 189-229.

${ }^{16}$ Este problema colocou-se desde cedo. Cf. PINTO, Frei Heitor - Imagem da Vida Cristã, prefácio e notas de Alves Correia, 2. ${ }^{a}$ edição, 1, Lisboa: Livraria Sá da Costa, 1952, p. 121-133. A partir do século XVII, houve mesmo questões resultantes da origem cristã nova de algumas freiras. Cf. MEA, Elvira Azevedo - 1621-1634. Coimbra, O Sagrado e o 
parte do quotidiano de algumas casas. Em 1672, quando o arcebispo de Braga visitou o convento de Santa Clara, de Guimarães, ordenou e exortou "com entranhas paternais que se lembrem da obrigação que tem de se tratarem e comonicarem com muita charidade como irmans spirituais e considerem que ainda nas pessoas seculares he estranhado injuriarem-se de palavras e assim devem ser mui reportadas e comedidas nesta parte e particularmente em falarem em gerasois e fidalguias e nobrezas e menos em se porem hũas as outras mãos violentas" ${ }^{17}$. Mas, a exortação do arcebispo não teve efeito. Em 1718, outro prelado, D. Rodrigo de Moura Teles, queixou-se do "pouco fruto [...] tirado das nossas vizitas passadas"18 e, no particular das injúrias relativas às origens familiares, verificou que se mantinham e concluiu afirmando "como que se nas filhas de Santa Clara possão ser mais hũas que as outras como irmãs e esposas de Jesus Christo"19. A situação era semelhante à que frei Baltazar de Azevedo e frei Aleixo de Azevedo encontraram em 1707 e em 1716 no mosteiro cisterciense de São Bento de Cástris, da arquidiocese de Évora ${ }^{20}$.

Profano em Choque. Revista de História das Ideias, 9, tomo 2 (1987), p. 229-248; REIS, Maria de Fátima Dias dos - Um Conflito de Poderes: A 'Sedição' das Freiras do Convento de Santa Clara de Santarém e os Problemas da Aplicação do Beneplácito Régio em Meados do Século XVIII. In Amar, Sentir e Viver a História. Estudos de Homenagem a Joaquim Veríssimo Serrão, 2, Lisboa: Colibri, 1995, p. 933-935; SANTOS, Georgina Silva dos - Isabel da Trindade: o Criptojudaísmo nos Conventos Portugueses Seiscentistas. In VAINFAS, Ronaldo, SANTOS, Georgina Silva dos, NEVES, Guilherme Pereira das (ed.) - Retratos do Império. Trajetórias Individuais no Mundo Português nos séculos XVI a XIX. Niterói: Eduff, 2006, p. 333-340; Idem, Entre Jesús y Moisés: el Marranismo en los Conventos Ibéricos durante el siglo XVII. In Historias Compartidas. Religiosidad y Reclusión Femenina en España, Portugal y América, silos XV-XIX. León: Universidad de León, 2007, p. 195-210; Idem, A Face Oculta dos Conventos: Debates e Controvérsias na Mesa do Santo Ofício. In VAINFAS, Ronaldo, e MONTEIRO, Rodrigo Bentes. Império de Várias Faces. Relações de Poder no Mundo Ibérico da Época Moderna. São Paulo: Alameda, 2009, p. 141-150. Em outros espaços europeus aconteciam situações idênticas. Cf. EVANGELISTI, Silvia Nuns. A History of Convent Live..., p. 30.

${ }^{17}$ Braga, ADB, Visitas e Devassas, liv. 68, fol. 12.

${ }^{18}$ Braga, ADB, Visitas e Devassas, liv. 68, fol. não numerado.

${ }^{19}$ Braga, ADB, Visitas e Devassas, liv. 68, fol. 70.

${ }^{20}$ CONDE, Maria Antónia Marques Fialho Costa - Cister a Sul do Tejo: o Mosteiro de São Bento de Cástris e a Congregação Autónoma de Alcobaça (1567-1776). Évora: Dissertação de Doutoramento em História apresentada à Universidade de Évora, 2004, p. 424. 
A barafunda atingia outras vertentes. $O$ gosto e a exibição de animais domésticos ${ }^{21}$ como cães, gatos e aves, eram um factor de destabilização no espaço conventual: barulho, reboliço e falta de higiene eram as consequências mais imediatas. Assim, em 1637, D. Sebastião de Matos de Noronha, ao visitar o convento do Salvador, de Braga, e o convento de Nossa Senhora dos Remédios da mesma cidade, ordenou que "pella grande indecencia que he andarem galinhas e outros animais no claustro e no interior do convento como são carneiros, cabritos, perus e outros semelhantes" fossem os referidos animais abatidos e consumidos pelas freiras enfermas ${ }^{22}$. Porém, o problema não ficou resolvido. Numa outra visitação, à segunda casa religiosa referida, em 1644, o chantre D. Luís Álvares Pinto fez notar a necessidade de cumprir a determinação do arcebispo e, consequentemente, enviar as galinhas ao “ospital sem remissão" e impedir a presença de cães e papagaios no coro ${ }^{23}$. Em 1672, a desobediência ainda persistia no mesmo convento e no de Santa Clara, de Guimarães, ambos visitados por D. Veríssimo de Lencastre, o qual proibiu, mais uma vez, as freiras de "na clausura e menos nas varandas não andarão galinhas nem outras aves semelhantes por se atalhar a imundicia que cauzão"24. Em 1705, a situação parecia ser insustentável. O arcebispo D. Rodrigo de Moura Teles, ao visitar o mosteiro do Salvador, de Braga, notou que, ao contrário do que sucessivamente tinha sido proibido, "se conservam algumas cadelinhas e caens e a estas as levão suas donas ao coro tendo-as nos regaços e juntamente gatos que brigando perturbão gravemente o sossego delle como também tem caens de fila o que tudo causa escândalo assim pello lugar a que o levão como pelo pouco respeito com que tratão as ordens de seus prelados”25. Outros espaços conventuais femininos alojaram cães, gatos e aves durante os séculos XVII e XVIII, tais são os casos do

${ }^{21}$ Sobre cães e gatos na vivência dos leigos da Época Moderna, cf., respectivamente, BRAGA, Paulo Drumond - História dos Cães em Portugal. Das Origens a 1800. Lisboa: Hugin, 2000; MARQUES, A. H. de Oliveira - Introdução à História dos Gatos em Portugal. In TENGARINHA, José. A Historiografia Portuguesa Hoje. São Paulo: Hucitec, 1999, p. 46-59.

${ }^{22}$ Braga, ADB, Visitas e Devassas, liv. 30, fol. 27 e liv. 19, fol. 24.

${ }^{23}$ Braga, ADB, Visitas e Devassas, liv. 19, fol. 32.

${ }^{24}$ Braga, ADB, Visitas e Devassas, liv. 19, fol. 40 e liv. 68, fol. 55.

${ }^{25}$ Braga, ADB, Visitas e Devassas, liv. 30, fol. 65v. 
Bom Jesus, de Monforte ${ }^{26}$, de Santa Clara, de Beja ${ }^{27}$, de Santa Clara, de Portalegre ${ }^{28}$, de Santa Clara, do Porto ${ }^{29}$, de Santa Clara, de Santarém ${ }^{30}$ e de São Bento de Cástris, onde, no final do Seiscentos, tanto o arcebispo de Évora quanto o visitador se mostraram irredutíveis, apesar de, em meados de Setecentos, o problema se continuar a verificar, sendo decretada a morte dos canídeos que entrassem na clausura pela portaria ${ }^{31}$.

O gosto pela vida mundana assumiu outros contornos. Referimo-nos aos divertimentos. Em vários espaços conventuais houve lugar para levar à cena representações teatrais de carácter profano, as quais eram, naturalmente, proibidas $^{32}$. Assim, foram detectadas tais práticas no Salvador, de Braga, em 1641, dando continuidade ao passado ${ }^{33}$ mas, em 1743, já estavam irradiadas pois, o arcebispo D. José de Bragança foi informado de que "foi costume fazerem-se alguns entremezes e outras representações em dia de Reis e outras festas fazendo papeis as religiozas que se vestiam conforme elles pediam porem ja ha tempos não houve função alguma"34. No século XVII, o mesmo ocorreu em Santa Clara, de Guimarães pois, em 1685, o arcebispo D. Luís de Sousa proibiu-as sob pena de excomunhão maior, afirmando ainda que "he prohibido por muitas leis eclesiásticas que nas igrejas e adros dellas se representem comedias e se nos propôs que na deste convento se representou hũa ainda este anno e com mais particulares circunstancias para estranhar se

${ }^{26}$ CAIERO, Maria Margarida Castro Neves Mascarenhas - Clarissas em Portugal. A Província dos Algarves. Da Fundação à Extinção. Em busca de um Paradigma Religioso Feminino, Lisboa: Dissertação de Doutoramento em História e Teoria das Ideias apresentada à Faculdade de Ciências Sociais e Humanas da Universidade Nova de Lisboa, 2006, p. 443.

${ }^{27}$ Lisboa, Biblioteca Nacional de Portugal (BNP), Cod. 8398, fols 149v-150.

${ }^{28}$ CAIERO, Maria Margarida Castro Neves Mascarenhas - Clarissas em Portugal..., p. 443.

${ }^{29}$ FERNANDES, Maria Eugénia Mata - O Mosteiro de Santa Clara do Porto em meados do século XVIII (1730-80). Porto: Arquivo Histórico da Câmara Municipal do Porto, 1992, p. 205.

${ }^{30}$ REIS, Maria de Fátima Dias dos - Um Conflito de Poderes: a 'Sedição' ..., p. 935.

${ }^{31}$ CONDE, Maria Antónia Marques Fialho Costa - Cister a Sul do Tejo..., p. 423.

${ }^{32} \mathrm{O}$ uso do teatro com fins recreativos e pedagógicos tão ao gosto dos jesuítas não era aceite pelos visitadores pois, de um modo geral, as freiras estavam mais interessadas no divertimento e até nos contactos com o sexo masculino do que nas funções catequéticas das representações, apesar de algumas escreverem peças de teatro. Cf. EVANGELISTI, Silvia - Nuns. A History of Convent Life..., p. 99-112.

${ }^{33}$ Braga, ADB, Visitas e Devassas, liv. 30, fol. 34v.

${ }^{34}$ Braga, ADB, Visitas e Devassas, liv. 40, fol. 11. 
por nos dizerem que aquella reprezentação se fez de noite" ${ }^{35}$. Nos Açores, concretamente no convento da Glória, do Faial, tais práticas foram proibidas logo na primeira visita, em $1675^{36}$. Em 1709, também o abade geral dos cistercienses, frei António do Quintal, considerou que o espaço sagrado não deveria ser profanado com representações teatrais mesmo que as mesmas fossem de carácter espiritual, proibindo, assim, essa prática comum em São Bento de Cástris ${ }^{37}$.

A ligação ao mundo profano foi igualmente visível através do uso de produtos como o tabaco e da comercialização de doces. Ora, o tabaco começou por integrar as chamadas drogas, palavra que nos séculos XVI a XVIII designava um conjunto de substâncias naturais utilizadas quer na alimentação quer na medicina, sem esquecer possíveis aproveitamentos na tinturaria ou até uso por mero prazer ${ }^{38}$. Podia ser inalado, fumado e mascado. Laicos e eclesiásticos não escapavam à moda. Por exemplo, quer as ordens masculinas quer as femininas não deixavam de recorrer ao uso do tabaco em pó e em folhas, desde o século XVII ${ }^{39}$. Porém, as vozes contra o consumo por recreação começaram a fazer ouvir-se. Entre os Portugueses destaque-se a do padre Jerónimo da Mota, abade de Santa Maria de Mujães, termo de Barcelos ${ }^{40}$. Apesar de o consumo estar documentado em diversas casas religiosas as proibições fizeram sentir-se, pelo menos desde 1701. Assim, o fez D. Rodrigo de Moura Teles em visita a Santa Clara,

${ }^{35}$ Braga, ADB, Visitas e Devassas, liv. 68, fol. 34.

${ }^{36}$ MATOS, Artur Teodoro de - Virtudes e Pecados das Freiras do Convento da Glória da Ilha do Faial (1675-1812): Uma Devassa à sua Intimidade. In O Faial e a Periferia Açoriana nos séculos XV a XX. Faial: Núcleo Cultural da Horta, 1998, p. 159.

${ }^{37}$ CONDE, Maria Antónia Marques Fialho Costa-Cister a Sul do Tejo..., p. 471.

${ }^{38}$ CARNEIRO, Henrique - Transformações do Significado da Palavra 'Droga': das Especiarias Coloniais ao Proibicionismo Contemporâneo. In VENÂNCIO, Renato Pinto e CARNEIRO, Henrique (ed.) - Álcool e Drogas na História do Brasil. Paulo, Alameda, Belo Horizonte: PUC Minas, 2005, p. 11.

${ }^{39}$ Cf. GOMES, Eduarda Maria de Sousa - O Convento da Encarnação do Funchal. Subsídios para a sua História (1660-1777). Funchal: Centro de Estudos de História do Atlântico, 1995, p. 143-145: MATOS, Artur Teodoro de - Virtudes e Pecados das Freiras..., p. $158-159$.

${ }^{40}$ SILVA, Armando Barreiros Malheiro da - A 'Censura do Tabaco'do Padre Jerónimo da Mota e dois Escritos de Ribeiro Sanches. Braga: Arquivo Distrital de Braga, 1986, p. 53-58. 
de Guimarães, em $1715^{41}$ e, em 1713, ao Salvador, de Braga, onde o tabaco era produzido e comercializado, dando origem a escândalos públicos e a problemas com a Coroa, levando o arcebispo a escrever: "por nos constar legalmente que neste nosso convento se sêmea tabaco na horta e se vende como se fosse estanque publico de que não so se segue grande prejuizo a fazenda real e estanqueiros e se ficam defraudando muito os rendimentos do seu contrato mas por este modo nos metem em questoens com a jurisdição secular como de presente nos esta sucedendo [...] se devem abster desta indesente escrupuloza e arriscada manufactura" ${ }^{42}$.

As comunidades femininas dedicaram-se frequentemente à doçaria para consumo próprio, oferta e comercialização ${ }^{43}$. Porém, nem sempre a actividade esteve isenta de questões, nomeadamente em algumas épocas do calendário litúrgico. Em 1644, D. Luís Álvares Pinto, ao visitar Nossa Senhora dos Remédios, de Braga, considerou e ordenou que "por evitar inquietações que as religiozas tem no tempo do Natal dos doces que fazem para as consoadas com que se esquecem da obrigação que tem assi na assistencia ao choro como no maes que pertence ao culto divino a que so devem attender e acodir deixando tudo o maes que as pode disviar e alhear deste intento mando a todas as religiozas deste mosteiro que daqui em diante não fação consoadas e se tire de todo este mao costume pello inconveniente que delle resulta" ${ }^{4}$. Nem a perspectiva de cair em excomunhão demoveu as freiras, pois, em 1672, entendeu o arcebispo de Braga, D. Veríssimo de Lencastre, que de dia de Todos os Santos até ao Natal as referidas freiras bem como as de Santa Clara, de Guimarães, desrespeitavam a proibição de preparar doces de forno e doces fritos além de pratos da consoada ${ }^{45}$. Outro visitador, D. Rodrigo de Moura Teles, verificou o mesmo, em 1705, 1718 e 1724. Assim, começou por lembrar que "os conventos são cazas de Deos aonde so se deve cuidar em louvores seus [...] o que suposto quanto humanamente podemos julgar não deve ser agradado de que nos seus conventos de

${ }^{41}$ Braga, ADB, Visitas e Devassas, liv. 68, fol. 57.

${ }^{42}$ Braga, ADB, Visitas e Devassas, liv. 30, fols 75v-76.

${ }^{43}$ Cf. ALGRANTI, Leila Mezan. Doces de Ovos, Doces de Freiras: a Doçaria dos Conventos portugueses no Livro de Receitas da Irmã Maria Leocádia do Monte do Carmo (1729). Cadernos Pagu. 17-18 (2001-2002), p. 397-408.

${ }^{44}$ Braga, ADB, Visitas e Devassas, liv. 19, fol. 32.

${ }^{45}$ Braga, ADB, Visitas e Devassas, liv. 19, fol. 43 e liv. 68, fol. 14v. 
religiozas haja comercios alheyos do seu estado com qualquer pretexto que seja pelo que prohibimos que dqui em diante possão as religiozas fazer conservas pera negociação e contracto e so lhe damos a faculdade de poder cada hũa dellas lavrar athe seis arrobas de assucar no discurso do anno pera suas obrigações e parentes" ${ }^{\text {"46 }}$. Em 1718 e em 1724, a situação mantinha-se, sendo costume as freiras ultrapassarem as referidas seis arrobas de açúcar e "contratarem" os doces ${ }^{47}$, ignorando as ordens do visitador.

Em termos alimentares, era suposto que as comunidades se pautassem por um certo ascetismo. Porém, nem sempre assim acontecia. Algumas tinham uma alimentação rica e variada ${ }^{48}$, de tal modo que o luxo à mesa chegou a ser manifesto, tal como entre alguns seculares ${ }^{49}$. Assim aconteceu em Nossa Senhora dos Remédios, de Braga, onde D. Sebastião de Matos de Noronha, em 1637, ordenou que nos dias de maior penitência (quartas, sextas e sábados), tinha a abadessa que mandar providenciar cação, bacalhau e outros peixes secos para evitar atitudes relaxadas, mais advertindo que "quando não houver peixe fresco na terra em presso que caiba na ração que se da em dinheiro às religiozas e quando falte tudo haja provizão de ovos para que com dous ovos e hũas ervas guizadas com charidade e amor possão passar e às noites se lhes dará sempre pello menos hum ovo com hum piqueno de queijo ou fruta quando houver"50. Idêntico problema se verificou no Salvador, de Braga, no mesmo ano ${ }^{51}$.

As vaidades no convento foram mais longe. Algumas freiras mantiveram os gostos que tinham no mundo secular no que se refere ao vestuário, aos

${ }^{46}$ Braga, ADB, Visitas e Devassas, liv. 68, fol. 44.

${ }^{47}$ Braga, ADB, Visitas e Devassas, liv. 68, fols 62v e 72.

${ }^{48}$ Cf. FERNANDES, Maria Eugénia Mata - O Mosteiro de Santa Clara do Porto..., p. 175-185; GOMES, Eduarda Maria de Sousa - O Convento da Encarnação do Funchal..., p. 130-143; SOUSA, Cristina Maria André de Pina e GOMES, Saul António - Intimidade e Encanto. O Mosteiro Cisterciense de Santa Maria de Cós (Alcobaça). Leiria: Edições Magno, 1998, p. 134-136; CONDE, Maria Antónia Marques Fialho Costa - Cister a Sul do Tejo..., p. 392-418; CAEIRO, Maria Margarida Castro Neves Mascarenhas - Clarissas em Portugal..., p. 343-355.

${ }^{49}$ Sobre a alimentação dos leigos no século XVIII, cf. BRAGA, Isabel M. R. Mendes Drumond - Alimentação, Etiqueta e Sociabilidade em Portugal no século XVIII. In Idem, Cultura, Religião e Quotidiano. Portugal (século XVIII). Lisboa: Hugin Editores, 2005, p. 167-231.

${ }^{50}$ Braga, ADB, Visitas e Devassas, liv. 19, fol. 22v.

${ }^{51}$ Braga, ADB, Visitas e Devassas, liv. 30, fol. 24v. 
adornos e até ao uso de cosméticos, mostrando inclusivamente que estavam a par da moda ${ }^{52}$. Ora, se o vestuário era o principal sinal externo de distinção social e de pertença a um grupo, o hábito monástico marcava o abandono da vida mundana e assumia um valor simbólico através da uniformização e da austeridade, isto é, o hábito evidenciava a pobreza, o anonimato e a castidade, pois era confeccionado com tecidos pobres, cores mortas e com feitios que escondiam as formas, de tal modo que camuflava qualquer eventual atractivo feminino. Os principais desvios passaram pelo uso de jóias, tecidos e sapatos de luxo, peças típicas do século, cores garridas e exibição dos cabelos e dos pescoços.

Em 1637, D. Sebastião de Matos de Noronha verificou que em Nossa Senhora dos Remédios, de Braga, havia diversos abusos e proibiu-os, considerando que às freiras estava proibida: "a garganta a [a]parecer nem brincos de orelhas de ouro ou de vidros, nem pessa de ouro algũa que apareça nem guedelhas ou cabelos que apareção, nem fitas de cores nem coletes com rozas dellas nem nos jubões ponhão atacas de seda de que fazem rosas nem jubões de seda qualquer que seja nem debruns della nem vasquinhas acolchoadas nem meas e sapatos nem camisas lavradas de negro nem de outra cor algũa nem com rendas e pespontos da vaidade secular nem manteos vermelhos nem posturas nos rostos" ${ }^{53}$. Em 1685, o arcebispo D. Luís de Sousa voltou à questão, referindo os excessos nos decotes, a exibição de toucados grandes e de formas diferentes das que estavam prescritas e o uso de hábitos e mantos de seda ${ }^{54}$. As observações, críticas e proibições não tiveram eco pois, em 1713, D. Rodrigo de Moura Teles deparou-se com cabelos apolvilhados e não totalmente cobertos, decotes grandes, uso de fitas, luvas, arrecadas e cruzes de ouro e diamantes ${ }^{55}$. Na visita de 1724 ,

${ }^{52}$ SUCENA, Berta de Moura - Corpo, Moda e Luxo em Portugal no século XVIII. Lisboa: Dissertação de Mestrado em História Moderna apresentada à Faculdade de Letras da Universidade de Lisboa, 2007. Cf. também EVANGELISTI, Silvia - Nuns. A History of Convent Life..., p. 29; TORREMOCHA HERNÁNDEZ, Margarita - Consumo de Vanidades: Afeites, Galas y Adornos en la Mujer Española del Seiscentos. XXVIII Encontro da Associação Portuguesa de História Económica e Social, Guimarães, 2008 ( http://www.neps.ics.uminho. pt/aphes28, consultado a 9 de Abril de 2009).

${ }_{53}$ Braga, ADB, Visitas e Devassas, liv. 19, fol. 18.

${ }^{54}$ Braga, ADB, Visitas e Devassas, liv. 19, fols 50-50v.

${ }^{55}$ Braga, ADB, Visitas e Devassas, liv. 19, fol. 88v. 
o luxo e as profanidades continuava e, mais uma vez, foram estranhados e proibidos. Desta feita, o prelado referiu arrecadas de ouro com pedras e aljôfares e uso cosméticos e de tranças nos cabelos ${ }^{56}$.

Em Nossa Senhora da Conceição, de Braga, a situação era afim. O arcebispo D. Luís de Sousa, em 1685, detectou o uso de fitas de prata e de ouro nos escapulários e vasquinhas de cores "desonestas" 57 . Anos depois, em 1718, D. Rodrigo de Moura Teles proibiu luxos semelhantes: toalhas de cabelo com rendas, luvas e leques com fitas e rendas, arrecadas, brincos com diamantes, cruzes de ouro ao pescoço e pós na cara e nos cabelos ${ }^{58}$. Em 1724, a situação mantinha-se ${ }^{59}$.

No convento do Salvador, em Braga, os problemas com o uso de vestuário e adornos foram visíveis desde a visita de 1620, a primeira cuja documentação nos chegou. Assim, o visitador proibiu todo o género de seda, passamanes e outras guarnições nos punhos, nos toucados e nos gibões; anéis de ouro ou prata e até panos de armar, guadamecis e pinturas profanas para decorar as celas ${ }^{60}$. Em 1637, D. Sebastião de Matos de Noronha insistiu nos mesmos assuntos referindo que só estavam autorizados certos tecidos vulgares nas cores preta e roxa ${ }^{61}$. Uma devassa de 1743, à mesma casa, deu conta do uso de brincos de ouro e prata com pedras, hábitos, gibões, capas e escapulários de seda ${ }^{62}$.

Outros espaços conheceram os mesmos problemas. No convento da Glória, do Faial, foram detectadas freiras que usavam fitas, rendas, luvas, meias de seda e sapatos de salto alto ${ }^{63}$. Em Santa Clara, de Portalegre, e no Bom Jesus, de Monforte, a riqueza dos trajes e dos sapatos e o uso de jóias fez-se notar igualmente durante o século XVII ${ }^{64}$, enquanto em São Bento

${ }^{56}$ Braga, ADB, Visitas e Devassas, liv. 19, fol. 112.

${ }^{57}$ Braga, ADB, Visitas e Devassas, liv. 18, fol. não numerado.

${ }^{58}$ Braga, ADB, Visitas e Devassas, liv. 18, fol. não numerado.

${ }^{59}$ Braga, ADB, Visitas e Devassas, liv. 18, fol. não numerado.

${ }^{60}$ Braga, ADB, Visitas e Devassas, liv. 30, fol. não numerado.

${ }^{61}$ Braga, ADB, Visitas e Devassas, liv. 30, fol. 18v.

${ }^{62}$ Braga, ADB, Visitas e Devassas, liv. 40, fols 8, 11. 16. Em certas casas, o luxo dos têxteis abrangeu também a decoração das celas. Cf. EVANGELISTI, Silvia - Nuns. A History of Convent Life..., p. 29 e 53-54.

${ }^{63}$ MATOS, Artur Teodoro de - Virtudes e Pecados das Freiras ..., p. 162.

${ }^{64}$ CAEIRO, Maria Margarida Castro Neves Mascarenhas - Clarissas em Portiugal..., p. $458-459$. 
de Cástris, em 1691, foram arroladas fitas nos toucados, rendas, chapéus de plumas, sapatos de cor, aljôfares, arrecadas, botões de ouro e jóias de ouro, pérolas e diamantes. Em 1713 e 1719, foram proibidos gibões à "alemoa" e camisas à francesa, além do uso de rendas nas mangas ${ }^{65}$. Por seu lado, em Santa Clara, de Guimarães, em 1759, o visitador Doutor Domingos Martins da Cruz Marques, tomou conhecimento do uso de espartilhos, sapatos de veludo com fivelas, fitas, rendas e exibição de pescoços descompostos ${ }^{66}$.

No mundo ocidental, o uso de cosméticos, entendidos como produtos para limpar, corrigir, proteger, embelezar e retardar o envelhecimento cutâneo ou conservar e restabelecer a beleza dos dentes e dos cabelos ${ }^{67}$, difundiu-se durante o Renascimento, apesar de se terem verificado diversas resistências. O berço destas práticas, tal como o da estética em geral, foi a península itálica. Mas, um pouco por todo o lado, as críticas aos enfeites luxuosos, às modas e aos cosméticos marcou discursos de teólogos e moralistas, tendo também presença no teatro e na literatura dita popular. Efectivamente, os discursos moralistas interpretavam o luxo, a sumptuosidade do vestuário e o uso de cosméticos como uma estratégia de sedução feminina ${ }^{68}$. Por seu lado, os tratados sobre educação também não fugiram a este tipo de posicionamento. Isto é, neles defendeu-se que as mulheres não deveriam alterar a cor dos cabelos, apesar da preferência pelos cabelos louros ser uma realidade ${ }^{69}$.

As tonalidades cromáticas da maquilhagem eram reduzidas. Importava apenas o branco da pele em geral e o vermelho do rosto. O branco era sinónimo de pureza e a cor da beleza da pele por excelência. Era também sinal de distinção social, só as mulheres que podiam permanecer em casa se mantinham brancas, as que tinham actividades servis andavam e trabalhavam

${ }^{65}$ CONDE, Maria Antónia Marques Fialho Costa - Cister a Sul do Tejo..., p. 419-423.

${ }^{66}$ Braga, ADB, Visitas e Devassas, liv. 73, fol. não numerado.

${ }^{67}$ Sobre o conceito e a finalidade dos cosméticos, cf. PITA, João Rui - Breve História dos Cosméticos. Munda. 32 (1996), p. 17-28; REBELO, Maria de Lourdes Godinho e PITA, João Rui - Cosméticos: sua evolução. Medicamento, História e Sociedade. 8 (1988), p. 23-28; BARATA, Eduardo A. F. - Cosméticos. Arte e Ciência. Lisboa, Porto, Coimbra: [s.n.], 2002.

${ }^{68}$ Cf. BRAGA, Isabel M. R. Mendes Drumond - Beleza e Sedução: à volta dos Cosméticos. In idem - Vivências no Feminino. Poder, Violência e Marginalidade nos séculos XV a XIX. Lisboa: Tribuna da História, 2007, p. 147-180.

${ }^{69}$ BUESCU, Ana Isabel - Imagens do Príncipe. Discurso Normativo e Representações (1525-49). Lisboa: Cosmos, 1996, p. 229-230. 
na rua, consequentemente, ficavam morenas pela acção do sol. Por seu lado, o encarnado era a cor da saúde, da perfeição, resultante do sangue em movimento. Para embranquecer a pele usava-se solimão ou alvaiade, este último de origem árabe, muito em voga durante os séculos XVI a XVIII. Para corar a face recorria-se ao uso de concela ou revol. No século XVIII, fabricavam-se os encarnados com cochinilha, madeira do Brasil e orcaneta da Provença e do Languedoc, sendo visível a escolha de tons adaptados à expressão dos sentimentos, da sensibilidade e da luz ${ }^{70}$.

Nos conventos a utilização de cosméticos era mais vulgar do que se possa pensar, embora das mulheres que tinham feito votos fosse de esperar que ficassem alheias a modas, luxos e cosméticos. Mas tal nem sempre acontecia. Em 1531, na visita efectuada por D. Edme de Saulieu aos estabelecimentos cistercienses da Península Ibérica, foi visível um desvio significativo à regra. Em Almoster, a cela de Leonor Mendes poderia ser comparada a um apartamento, onde não faltavam luxos diversos, entre os quais perfumes: "dans l'une des chambres résidait une moniale, nièce de ladite Leonor, très curiosement entournée de flacons d'eaux distillés diverses, de boîtes de pharmacie, de parfuns, etc." 71 . Mais tarde, em 1620, D. Rodrigo da Cunha proibiu "todo o genero de posturas no rosto" às religiosas do Salvador,

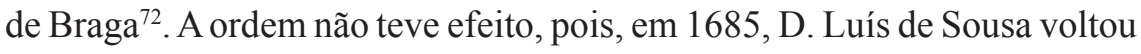
a insistir na questão ${ }^{73}$. Nesse mesmo ano, o prelado, ao visitar Santa Clara, de Guimarães, fez o mesmo, ou seja, proibiu totalmente às religiosas o uso de "cor ou branco ou outras semelhantes posturas e sob pena de obediência lhes mandamos não usem de alguas dellas por serem todas estranhadas

${ }^{70}$ VIGARELLO, Georges - Histoire de la Beauté. Le Corps et l'Art d'Embellir de la Renaissance à nos Jours. Paris: Seuil, 2004, p. 116-117.

${ }^{71}$ BRONSEVAL, Claude de - Peregrinatio Hispânica. Voyage de Dom Edme de Saulieu, Abbé de Clairvaux, en Espagne e au Portugal (1531-1533), introdução, tradução e notas de Maur Cocheril. tomo 1, Paris: Presses Universitaires de France, 1970, p. 377. No Brasil colonial, por exemplo, no convento do Desterro (Baía) também se verificaram casos de freiras com cabelos brancos que os pintavam de negro, o que motivou críticas do bispo D. frei Manuel de Santa Inês, em 1764. Cf. SILVA, Maria Beatriz Nizza da - A Reclusão Feminina no Brasil Colonial. Anais de História de Além-Mar, 1 (2000), p. 211. De notar que as receitas caseiras para a preparação de cosméticos eram vulgares. Cf. BRAGA, Isabel M. R. Mendes Drumond - Beleza e Sedução ..., p. 147-180.

${ }^{72}$ Braga, ADB, Visitas e Devassas, liv. 30, fol. não numerado.

${ }^{73}$ Braga, ADB, Visitas e Devassas, liv. 30, fol. 49v. 
ainda nas mulheres seculares em quem as obrigações são menores e com mais cauza nas religiozas se devem reputar por mais indecentes, sendo certo de que o enfeite de que so devem tratar he o da fermozura das almas que he o que mais agrada a Christo Nosso senhor de quem são esposas"74. Mas os cosméticos eram uma tentação forte para algumas religiosas e, consequentemente, um hábito difícil de combater. Ainda em 1759, uma devassa à mesma casa, deu conta do uso de óleos e polvilhos no rosto por parte de algumas freiras. Alguns testemunhos são, porém, elucidativos do facto de certas religiosas criticarem tal prática: "usão de arteficios no rosto para afectarem de mais fermozura do que a que Deos thes $\mathrm{deo}^{75}$. Em 1685, foi a vez do arcebispo D. Luís de Sousa tomar conhecimento e proibir o uso, ainda que moderado no segundo caso, de cosméticos por parte de algumas freiras de Nossa Senhora dos Remédios, de Braga ${ }^{76}$, e de Nossa Senhora da Conceição, da mesma cidade: "foi-nos proposto que algumas religiozas punhão no rosto cor e outras posturas e supposto que também ouvimos que não havia grande demazia nellas devemos porem expor thes que em quem professa o seu estado qualquer continuação deste uso he digno de remédio e estranhado ainda nas mulheres seculares" 77 .

3. Apesar das determinações do Concílio de Trento e do empenho de alguns prelados, ao longo dos séculos XVII e XVIII, e não obstante muitos exemplos de elementos do clero cumpridores, continuaram a verificarse sérios desvios às normas quer entre elementos do clero secular quer entre os regulares dos dois sexos ${ }^{78}$. No caso das freiras, nem a cultura ou a produção intelectual de algumas evitou excessos por parte de outras ${ }^{79}$.

${ }^{74}$ Braga, ADB, Visitas e Devassas, liv. 68, fol. 28.

${ }^{75}$ Braga, ADB, Visitas e Devassas, liv. 73, fol. não numerado.

${ }^{76}$ Braga, ADB, Visitas e Devassas, liv. 19, fol. 49v.

${ }^{77}$ Braga, ADB, Visitas e Devassas, liv. 18, fol. não numerado.

${ }^{78}$ BRAGA, Paulo Drumond - Igreja, Igrejas e Culto. In MENESES, Avelino de Freitas de (ed.) - Portugal da Restauração ao Ouro do Brasil (= SERRÃO, Joel, e MARQUES, A. H. de Oliveira (ed.), Nova História de Portugal, 7). Lisboa: Presença, 2002, p. 90-129.

79 Cf. HATHERLY, Ana - A Preciosa de Sóror Maria do Céu. Edição actualizada do Códice 3773 da Biblioteca Nacional precedida de uma introdução histórica. Lisboa: Instituto Nacional de Investigação Científica, 1990; BELO, Filomena - Rellação da Vida e Morte da Serva de Deos a Veneravel Madre Elenna da Crus por Sóror Maria do Céu, transcrição do códice 87 da Biblioteca Nacional precedida de um estudo histórico, Lisboa: 
O disciplinamento não foi fácil, as resistências foram muitas e, apesar de a documentação compulsada ter resultado de uma sondagem aleatória, pode verificar-se que de Norte a Sul de Portugal, tal como aconteceu em outros pontos da Europa, as transgressões às regras fizeram parte do quotidiano levando a algumas situações de exaspero por parte dos visitadores.

Mesmo em arquidioceses como Braga e Évora, cujos arcebispos à época do Concílio - D. frei Bartolomeu dos Mártires e o cardeal infante D. Henrique, respectivamente - eram particularmente escrupulosos - o de Braga participou inclusivamente na terceira parte da reunião de Trento - logo no início de Seiscentos foram visíveis vários sinais de relaxamento entre a população conventual feminina. A pergunta que se coloca é: ainda não chegara o disciplinamento pós tridentino ou já se perdera? Efectivamente, se continuarmos o percurso até meados do século XVIII, o panorama não sofreu alterações. Os mesmos vícios persistiram. As resistências foram mais fortes que o disciplinamento. Ainda se promoveram esforços, que vieram a mostrar-se infrutíferos, ao criar, a 21 de Novembro de 1789, a Junta do Exame do Estado Actual e Melhoramento Temporal das Ordens Regulares. A instituição, criada pela Coroa, visava ajudar a proceder a uma reforma estrutural das ordens religiosas e deveria ser informada por escrito, por cada uma das casas religiosas, do valor e natureza das suas rendas, do património móvel e imóvel e das obrigações e encargos que as oneravam. Recolhidas estas informações e verificados os problemas, proporia alterações para racionalizar e, consequentemente, melhorar a situação de cada casa ${ }^{80}$. De qualquer modo, a solução encontrada para os problemas, a qual passou pela ponderação de outras realidades, nomeadamente do peso da população conventual inactiva, deu-se em 1834, com a extinção das Ordens.

Quimera, 1993; MORUJÃO, Isabel - Contributo para uma Bibliografia Cronológica da Literatura Monástica Feminina Portuguesa do Século XVII e XVIII. Impressos. Lisboa: Universidade Católica Portuguesa, 1995; Idem, Por Trás da Grade. Poesia Conventual Feminina em Portugal (Séculos XVII e XVIII). Porto: Dissertação de Doutoramento em Letras, especialidade Literatura Portuguesa, apresentada à Faculdade de Letras da Universidade do Porto, 2005; ALGRANTI, Leila Mezan - Conventos e Recolhimentos em Portugal e na América Portuguesa: Espaços de Leitura e de Escritas Femininas (Séculos XVII e XVIII). In Idem, Livros de Devoção, Atos de Censura. Ensaios de História do Livro e da Leitura na América Portuguesa (1750-1821). São Paulo: Hucitec, 2004, p. 23-74.

${ }^{80}$ CORREIA, José Eduardo da Horta - Liberalismo e Catolicismo. O Problema Congreganista (1820-1823). Coimbra: Universidade de Coimbra, 1974. 